\title{
APPLICATION OF PVDF ULTRAFILTRATION MEMBRANES TO TREAT AND REUSE TEXTILE WASTEWATER
}

\author{
V. Buscio, M. Crespi, C. Gutiérrez-Bouzán* \\ Institut d'Investigació Tèxtil i Cooperació Industrial de Terrassa (INTEXTER), \\ Universitat Politècnica de Catalunya-BarcelonaTech (UPC). \\ C/ Colom 15, 08222, Terrassa-Spain.
}

Corresponding author: Tel.: +34 9373980 08; fax: +34 937398272 .

E-mail addresses: gutierrez@intexter.upc.edu

\section{Abstract}

In this work, the feasibility of polyvinylidene difluoride (PVDF) ultrafiltration membranes to treat textile wastewater was studied. The C.I. Disperse Orange 30 and C.I. Disperse Rubine 73 were selected as pollutant for the membrane filtration study.

The results showed about $90 \%$ and $96 \%$ of COD decrease and dye removal, respectively. In addition, very low fouling was observed which demonstrated the feasibility of applying this type of membranes to treat textile wastewater.

Finally, after the membrane treatment, $100 \%$ of the obtained permeate was reused. Fabrics dyed with the reused water were evaluated respect to references carried out with softened tap water. No significant colour differences were observed between reference fabrics and the fabrics dyed with the permeate.

Keyword: Textile wastewater; Disperse dyes; Water reuse; Colour removal; Membrane treatment 
1- Introduction

Dyes are widely used in different industries such as textile, leather, paper, plastics, and food $[1,2]$. There are more than 100,000 different synthetic dyes and their annual production is about $7 \cdot 10^{5}$ tonnes [3]. Particularly, the textile industry consumes $10^{7} \mathrm{~kg}$ of dye per year [4] and $15 \%$ of dyes consumed are discharged into the textile wastewater [5] causing serious problems upon aquatic flora and fauna [6]. Dyes are classified according to their chemical structure and how they are applied in the dyeing process [7]. The most common dyes are reactive, acid, direct, vat and disperse $[8,9]$. Disperse dyes are non-ionic aromatic compounds with low solubility in water [10]. They are widely used in the dyeing of polyester fibre. This fibre represents about the $50 \%$ of the total world textile fibre consumption [11].

In general, dyes are difficult to remove because they are stable to light and oxidizing agents, and with low biodegradability $[12,13]$. The most used technologies to treat wastewater containing dyes are based on biological [14,15] or/and physical-chemical processes [16-18]. Although these treatments are able to meet legislative requirements, they do not allow water reuse in textile processes $[19,20]$. The reuse of textile wastewater is an important challenge since between 60 and $100 \mathrm{~L}$ of water are needed to produce a kilogram of textile product [21]. Other treatments such as photofenton [22], photocatalytic [23] and electrochemical [24] have been studied. These methods provided high colour removal but the generation of by-products and the high cost are their main limitations [25].

Membrane technology has shown great potential to treat textile wastewater as it can be applied to remove different kind of dyes. In addition, it allows both the reuse of auxiliary chemicals and some concentrate dyes [26] and produces a permeate with high quality, which can be reused in new textile processes [27]. In general, reverse osmosis (RO) $[28,29]$ and nanofiltration (NF) membranes $[30,31]$ are the most studied in the treatment of effluents containing dyes. The main limitation of membrane processes such as NF and RO is the decline of permeate flux caused by the accumulation of 
particles on the membrane surface [32]. This phenomenon is especially observed in $\mathrm{RO}$ membrane resulting in an increase of the treatment cost $[33,34]$. Ultrafiltration membranes (UF) exhibit low fouling and high efficiency to separate chemicals with high molecular weight or insoluble dyes like disperse.

On the basis of these considerations, the aim of this work is study the feasibility of PVDF ultrafiltration membranes to treat textile wastewater containing disperse dyes. Two different disperse dyes, C.I. Disperse Orange 30 (DO30) and C.I. Disperse Rubine 73 (DR73) were selected for the membrane filtration study. Subsequently, the permeate was reused in new polyester dyeings. Finally, fabrics dyed with the reused effluent were evaluated respect to references carried out with softened tap water.

\section{2- Experimental}

\section{1- Reagents}

Two disperse dyes provided by Archroma-Spain were selected for the study of permeate reuse: C.I. Disperse Orange 30 and C.I. Disperse Red 73. Figure 1 shows their chemical structures.

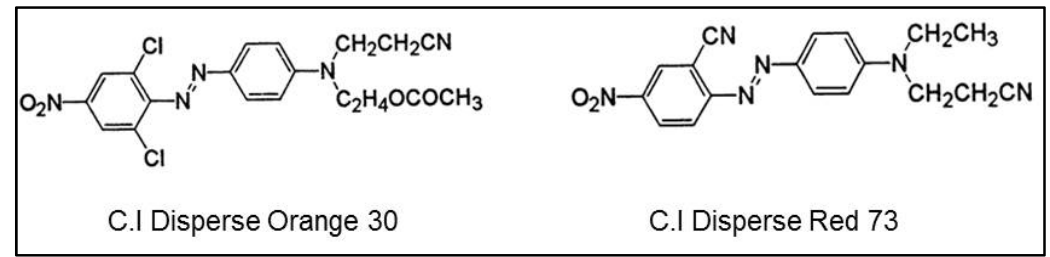

Figure 1- Chemical structure of C.I. Disperse Orange 30 and C.I. Disperse Red 73

To determine the dye concentration in the permeate, N,N-dimethylformamide (purity 99.5\%, Scharlau) and softened tap water were used as solvents.

The $\mathrm{pH}$ of synthetic effluents dye baths was adjusted with $\mathrm{NaOH}$ and $\mathrm{HCl}$

Sodium hypochlorite solution (6-14\% active chlorine) acquired from Sigma-Aldrich was used for the membrane cleaning. 
2.2- Synthetic effluents preparation

To simulate the effluents discharged after the dyeing process, four solutions of either DO30 or DR73 were prepared in softened tap water. The $\mathrm{pH}$ of the effluents was adjusted at 6.0-6.5. The main characteristics of the effluents used in this study are shown in Table 1.

Table 1- Effluents characterization

\begin{tabular}{|c|c|c|c|c|}
\hline Dye & $\mathrm{pH}$ & Conductivity $\left(\mu \mathrm{S} \cdot \mathrm{cm}^{-1}\right)$ & $\operatorname{COD}\left(\mathrm{mg} \cdot \mathrm{L}^{-1}\right)$ & Dye concentration $\left(\mathrm{mg} \cdot \mathrm{L}^{-1}\right)$ \\
\hline \multirow{2}{*}{ DO30 } & 6.4 & 1321 & 120.6 & 77.4 \\
\hline & 6.2 & 1359 & 102.5 & 76.1 \\
\hline \multirow{2}{*}{ DR73 } & 6.4 & 1557 & 106 & 77.2 \\
\hline & 6.3 & 1438 & 109 & 77.8 \\
\hline
\end{tabular}

\section{3- Membrane Treatment}

In this work, a PVDF hollow fibre membrane module ZeeWeed-1 (ZW-1) (GE Power \& Water, Canada) was used. Its main specifications and operation characteristics are shown in Table 2.

Table 2- ZW-1 Specifications

\begin{tabular}{lc}
\hline Model & ZW-1, Submersible Module \\
Configuration & Outside / In hollow Fiber \\
Membrane Surface & $0.05 \mathrm{~m}^{2}$ \\
Pore size & $0.04 \mu \mathrm{m}$ \\
Maximum Transmembrane Pressure (TMP) & $0.62 \mathrm{bar}$ \\
Typical Operating TMP & $0.1-0.5 \mathrm{bar}$ \\
Maximum TMP Back Wash & $0.55 \mathrm{bar}$ \\
Operating pH range & $5-9$ \\
\hline
\end{tabular}

A laboratory scale reactor was built to position the membrane module, according to its geometry and specific requirements (Figure 2). The membrane reactor was a $20 \mathrm{~L}$ cylindrical vessel. It was fed from a $20 \mathrm{~L}$ tank by a centrifugal pump. A peristaltic pump 
was used for the permeate effluent. The membrane module had an air inlet with the purpose to decrease the fouling. The laboratory scale reactor operated in cycles of 15 minutes of filtration and 30 seconds of backwashing with permeate.

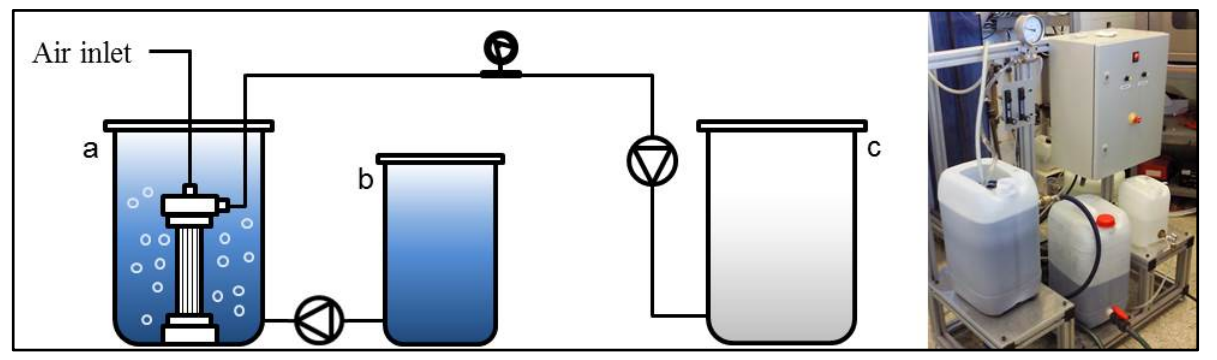

Figure 2- Laboratory scale reactor: a) Membrane reactor, b) Feed tank, c) Permeate tank

The membrane treatment was carried out at constant TMP ( 0.2 bar $)$ and at room temperature. A concentration factor of 10 was selected for this study. Finally, after each filtration process, the membranes were cleaned with a sodium hypochlorite solution $\left(5 \mathrm{mg} \cdot \mathrm{L}^{-1}\right)$.

\section{4- Permeate reuse}

The reuse dyeing tests were performed in a laboratory Ti-Color dyeing machine (Integrated Color Line) under the following conditions: $10 \mathrm{~g}$ of polyester fabric, dye concentration $3 \%$ o.w.f (over weight of fibre) and liquor ratio 1:20 (1 g fibre/20 mL dye bath). The dyeing method conditions are shown in Figure 3. 


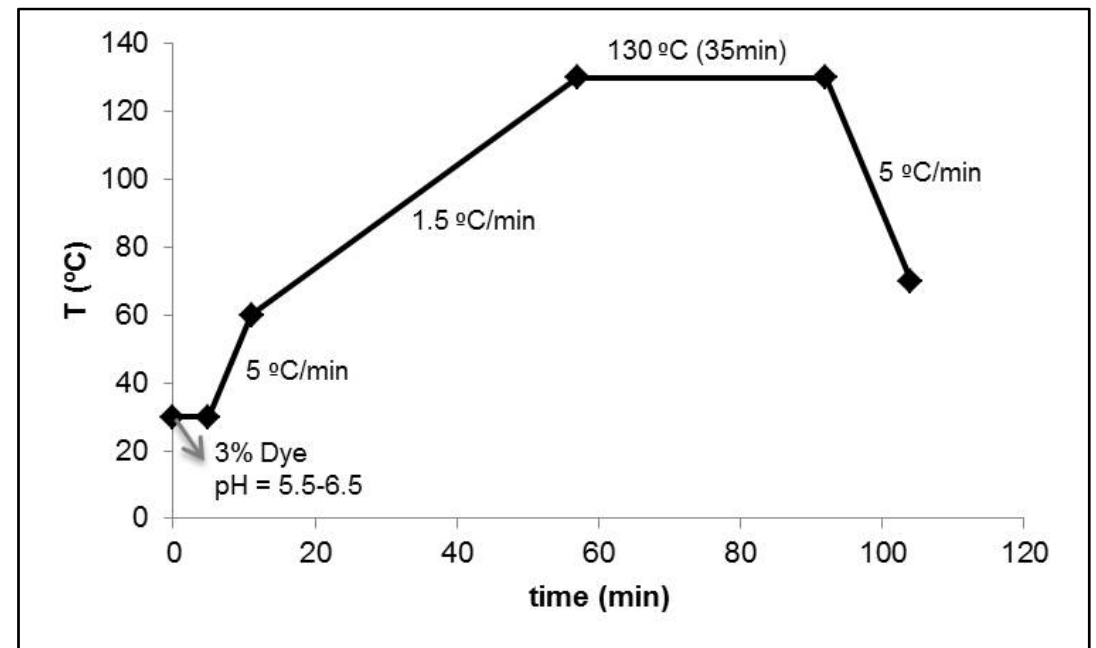

Figure 3- Dyeing method

\section{5- Analytical methods and Measurements}

The permeate flux was determined to evaluate the membrane fouling. It was determined by measuring the permeate volume collected in a certain period of time (Eq. 1)

$\mathrm{J}=\mathrm{V} / \mathrm{A} \cdot \Delta \mathrm{t}$

Where $J$ is the permeate flux $\left(L \cdot m^{-2} \cdot h^{-1}\right), A$ is the effective area of the membrane $\left(m^{2}\right)$ and $V$ is the collected volume in a time interval $\Delta t\left(L \cdot h^{-1}\right)$.

The dye removal $\left(\% R_{\text {dye }}\right)$ was calculated from concentrations of feed and permeate using the Eq. 2:

$\% R_{\text {dye }}=\left(\left(C_{f}-C_{p}\right) / C_{f}\right) \cdot 100$

where $C_{f}$ and $C_{p}$ are the concentrations of dye in feed and permeate, respectively. The dye was dissolved in an aqueous solution, which contained N,N-dimethylformamide 1:1, and determined with UV-Vis spectrophotometer UV-2401 (Shimadzu Corporation) at the maximum wavelength of the visible spectrum $(430 \mathrm{~nm}$ for DO30 and $528 \mathrm{~nm}$ for RD73). For each dye, the calibration curve was:

DO30: Abs $=0.0235 \cdot$ conc -0.0046 and $R^{2}=0.9997$

DR73: Abs $=0.0483 \cdot$ conc -0.0087 and $R^{2}=0.9996$ 
COD was determined according to the methods recommended by American Public Health Association [33]. The COD reduction $\left(\% R_{C O D}\right)$ was calculated using the Eq. 3: $\% R_{C O D}=\left(\left(C_{C O D}-C D_{p}\right) / C O D_{f}\right) \cdot 100$

where $\mathrm{COD}_{\mathrm{f}}$ and $\mathrm{COD}_{\mathrm{p}}$ are the COD values in feed and permeate respectively. The conductivity was measured following the method 2510 B [35] with a conductivity meter GLP 31 (CRISON). The pH was determined according to the method $4500 \mathrm{H}+\mathrm{B}$ [35] using a pH meter GLP 21 (CRISON).

The quality of dyed fabrics was studied from colour differences $\left(\mathrm{DE}_{\mathrm{CMC}(\mathrm{I}: \mathrm{c})}\right)$ using a Macbeth Colour Eye 7000A spectrophotometer. The difference in colour was determined in conformity with the Standard UNE-EN ISO 105-J03 [36]. The equation for $\mathrm{DE}_{\mathrm{CMC}(\mathrm{I}: \mathrm{c})}$ describes an ellipsoidal volume with axes in the direction of lightness $(\mathrm{L})$, chroma $(\mathrm{C})$, and hue $(\mathrm{H})$ centered about a standard. Colour difference is composed of three components:

- Lightness component $\left(\mathrm{DL}_{\mathrm{CMC}}\right)$ that is weighted by the lightness tolerance $\left(D L^{*} / I S_{L}\right)$. If $D L_{C M C}$ is positive, the reused dyeing is lighter than the standard. If $D L_{C M C}$ is negative, the reused dyeing is darker than the standard.

- Chroma component $\left(\mathrm{DC}_{\mathrm{CMC}}\right)$ that is weighted by the chroma tolerance $\left(D C^{*}{ }_{a b} / \mathrm{CS}_{\mathrm{c}}\right)$. If $\mathrm{DC}_{\mathrm{CMC}}$ is positive, the reused dyeing is more chromatic than the standard. If $\mathrm{DL}_{\mathrm{CMC}}$ is negative the reused dyeing is less chromatic than the standard.

- Hue component $\left(\mathrm{DH}_{\mathrm{CMC}}\right)$ that is weighted by the hue tolerance $\left(\mathrm{DH}^{*}{ }_{\mathrm{ab}} / \mathrm{S}_{\mathrm{H}}\right)$. It describes the difference between the hue angle of the standard and the hue angle of the reused dyeing in a polar coordinate.

Colour difference is calculated from the Eq. 4:

$D E_{C M C(I: C)}=\left[\left(D^{*} / I S_{L}\right)^{2}+\left(D C C^{*}{ }_{a b} / C_{c}\right)^{2}+\left(D^{*}{ }_{a b} / S_{H}\right)^{2}\right]^{1 / 2}$

The lengths of the semi axes of the ellipsoid are calculated from the values $L^{*}, C^{*}{ }_{a b, R}$ and $h_{a b, R}$, that correspond to the reference as follows: 
$S_{L}=0.040975 L^{*}{ }_{R} /\left(1+0.01765 L^{*}{ }_{R}\right)$ if $L^{*}{ }_{R} \geq 16$ or $S_{L}=0.511$ if $L^{*}{ }_{R}<16$

$S_{C}=\left[0.0638 C^{*}{ }_{a b, R} /\left(1+0.0131 C^{*}{ }_{a b, R}\right)\right]+0.638$

$\mathrm{S}_{\mathrm{H}}=(\mathrm{FT}+1-\mathrm{F}) \mathrm{S}_{\mathrm{c}}$

where

$\mathrm{F}=\left(\left(\mathrm{C}^{*} \mathrm{ab}, \mathrm{R}\right)^{4} /\left(\left(\mathrm{C}^{*} \mathrm{ab}, \mathrm{R}\right)^{4}+1900\right)\right)^{1 / 2}$

$T=0.36+\left|0.4 \cos \left(35+h_{a b, R}\right)\right|$ if $h_{a b, R} \geq 345^{\circ}$ or $h_{a b, R} \leq 164^{\circ}$

or $T=0.56+\left|0.2 \cos \left(168+h_{a b, R}\right)\right|$ if $164^{\circ}<h_{a b, R}<345^{\circ}$

In summary, a dyeing is considered acceptable when the $\mathrm{DE}_{\mathrm{CMC}}(\mathrm{l}: \mathrm{c})$ value is lower than 1, measured with Macbeth Colour Eye 7000A spectrophotometer with respect to a reference sample.

\section{3- Results and Discussion}

\section{1- Membrane treatment}

The synthetic dye baths were treated by means of an ultrafiltration membrane laboratory scale reactor. The trans-membrane pressure was set at 0.2 bar. Along the filtration process, the permeate flux remained constant at $20.9 \mathrm{~L} \cdot \mathrm{m}^{-2} \cdot \mathrm{h}^{-1}$ and $21.7 \mathrm{~L} \cdot \mathrm{m}^{-}$ ${ }^{2} \cdot \mathrm{h}^{-1}$ for DO30 and DR73 respectively. The low fouling observed in this laboratory scale reactor showed the feasibility of applying this type of membranes to treat textile effluents.

The efficiency of the membrane process in the treatment of textile effluents containing disperse dyes was determined by means of permeate characterization. Permeate samples were taken and analysed daily.

Both effluents showed similar behaviour producing high quality permeate. The $\mathrm{pH}$ and conductivity values did not change with respect to the initial effluent due to the low retention of inorganic ions by ultrafiltration membranes.

The treatment of DR73 exhibited $92 \%$ COD reduction and $97 \%$ dye removal $(8.5 \mathrm{mg} \cdot \mathrm{L}$ ${ }^{1}$ and $2.8 \mathrm{mg} \cdot \mathrm{L}^{-1}$ respectively). Similar results were also achieved for the DO30 effluent: $90 \%$ of COD decrease $\left(10.5 \mathrm{mg} \cdot \mathrm{L}^{-1}\right)$ and $95 \%$ of dye removal $\left(3.8 \mathrm{mg} \cdot \mathrm{L}^{-1}\right)$. 


\section{2- Selection of reference fabric}

Replicates of same dyeing can exhibit slight differences in their colour coordinates. For this reason, before the permeate reuse study, it is important to select properly for each dye the reference fabric. With this purpose, colour differences were measured and compared between replicates. All experiments were run in triplicate.

Table 3 shows the values of $\mathrm{DE}_{\mathrm{CMC}(2: 1)}$, $\mathrm{DL}, \mathrm{DC}$ and $\mathrm{DH}$ for fabrics dyed with $\mathrm{DO} 30$ and

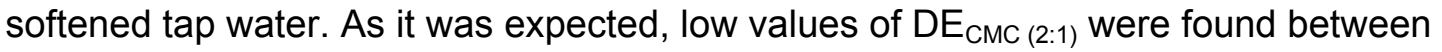

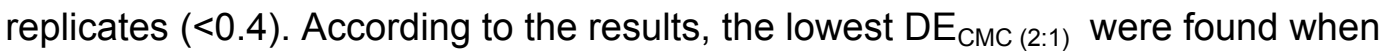
replicates 1 and 3 were compared with the replicate 2 . For this reason, the replicate 2 was selected as the reference fabric for $\mathrm{DO} 30$ dye and it was used with this purpose in the permeate reuse study.

Table 3- Colour differences obtained in reference fabrics dyed with DO30

\begin{tabular}{cccccccc}
\hline DE $_{\text {СMC(2:1) }}$ & $\mathbf{1}$ & $\mathbf{2}$ & $\mathbf{3}$ & $\mathbf{D L}$ & $\mathbf{1}$ & $\mathbf{2}$ & $\mathbf{3}$ \\
\hline $\mathbf{1}$ & $*$ & 0.18 & 0.38 & $\mathbf{1}$ & $*$ & -0.03 & -0.13 \\
$\mathbf{2}$ & 0.13 & $*$ & 0.21 & $\mathbf{2}$ & 0.03 & $*$ & -0.10 \\
$\mathbf{3}$ & 0.28 & 0.22 & $*$ & $\mathbf{3}$ & 0.13 & 0.14 & $*$ \\
& & & & & & & \\
\hline $\mathbf{D C}$ & $\mathbf{1}$ & $\mathbf{2}$ & $\mathbf{3}$ & $\mathbf{D H}$ & $\mathbf{1}$ & $\mathbf{2}$ & $\mathbf{3}$ \\
\hline $\mathbf{1}$ & $*$ & -0.06 & -0.13 & $\mathbf{1}$ & $*$ & -0.17 & -0.34 \\
$\mathbf{2}$ & -0.10 & $*$ & -0.07 & $\mathbf{2}$ & 0.08 & $*$ & -0.17 \\
$\mathbf{3}$ & -0.03 & -0.11 & $*$ & $\mathbf{3}$ & 0.24 & 0.12 & $*$ \\
\hline
\end{tabular}

The same procedure was carried out with DR73 dye (Table 4). In this case, $\mathrm{DE}_{\mathrm{CMC}(2: 1)}$ were higher than $\mathrm{DE}_{\mathrm{CMC}(2: 1)}$ with $\mathrm{DO} 30$ which means that the reproducibility of fabrics dyed with DR73 was lower. This fact was taken into account to evaluate the feasibility of permeate reuse. The replicate 1 was selected as the reference for DR73 dye. 
Table 4- Colour differences obtained in reference fabrics dyed with DR73

\begin{tabular}{cccccccc}
\hline $\mathbf{D E}_{\mathrm{CMC}(2: 1)}$ & $\mathbf{1}$ & $\mathbf{2}$ & $\mathbf{3}$ & $\mathbf{D L}$ & $\mathbf{1}$ & $\mathbf{2}$ & $\mathbf{3}$ \\
\hline $\mathbf{1}$ & $*$ & 0.63 & 0.19 & $\mathbf{1}$ & $*$ & -0.41 & -0.08 \\
$\mathbf{2}$ & 0.55 & $*$ & 0.59 & $\mathbf{2}$ & 0.34 & $*$ & 0.33 \\
$\mathbf{3}$ & 0.28 & 0.65 & $*$ & $\mathbf{3}$ & 0.00 & -0.29 & $*$ \\
& & & & & & & \\
\hline $\mathbf{D C}$ & $\mathbf{1}$ & $\mathbf{2}$ & $\mathbf{3}$ & $\mathbf{D H}$ & $\mathbf{1}$ & $\mathbf{2}$ & $\mathbf{3}$ \\
\hline $\mathbf{1}$ & $*$ & -0.38 & 0.08 & $\mathbf{1}$ & $*$ & 0.28 & 0.15 \\
$\mathbf{2}$ & 0.28 & $*$ & 0.47 & $\mathbf{2}$ & -0.33 & $*$ & -0.14 \\
$\mathbf{3}$ & -0.19 & -0.58 & $*$ & $\mathbf{3}$ & -0.20 & -0.10 & $*$ \\
\hline
\end{tabular}

\section{3- Permeate reuse}

The treated effluents were used in order to study the feasibility of the permeate reuse.

The dyeings were carried out with $100 \%$ of permeate. Dyeings obtained were evaluated with respect to a reference dyeing (selected in section 3.2).

Table 5 exhibits the values measured in the permeate reuse study. Fabrics referenced as 1-3 were dyed with the permeate obtained in the treatment of synthetic effluents containing DO30 dye. Fabrics referenced as 4-6 used permeate from synthetic effluents containing DR73 dye.

Table 5- Colour differences values in the permeate reuse study

\begin{tabular}{ccccccccc}
\hline & \multicolumn{3}{c}{ DO30 dye } & \multicolumn{5}{c}{ DR73 dye } \\
& DE $_{\text {CMC(2:1) }}$ & DL & DC & DH & DE $_{\text {CMC(2:1) }}$ & DL & DC & DH \\
\hline $\mathbf{1}$ & 0.54 & -0.23 & -0.49 & 0.04 & 0.65 & -0.29 & -0.58 & -0.10 \\
$\mathbf{2}$ & 0.55 & -0.26 & -0.32 & -0.37 & 0.66 & -0.41 & -0.51 & -0.09 \\
$\mathbf{3}$ & 0.64 & -0.36 & -0.39 & -0.36 & 0.72 & -0.37 & -0.62 & 0.01 \\
\hline $\mathbf{4}$ & 0.84 & 0.38 & 0.32 & 0.67 & 0.83 & 0.13 & 0.73 & 0.38 \\
$\mathbf{5}$ & 0.87 & 0.42 & 0.34 & 0.68 & 0.83 & 0.47 & 0.67 & 0.13 \\
$\mathbf{6}$ & 0.82 & 0.44 & 0.29 & 0.63 & 0.77 & 0.25 & 0.72 & 0.03 \\
\hline
\end{tabular}

From Table 5, it can be observed that dyeings showed $\mathrm{DE}_{\mathrm{CMC}(2: 1)}$ lower than 1, which is the maximum value accepted at industrial scale. For dyeings 1-3, $\mathrm{DE}_{\mathrm{CMC}(2: 1)}$ values 
were mainly due to the influence of DC. The negative values of $D C$ and $D L$ mean that dyeings were less chromatic and darker than the replicates.

Regarding dyeings 4-6, fabrics dyed with permeate from synthetic effluents containing DR73 dye, exhibited $D E_{C M C(2: 1)}$ higher than dyeings 1-3. This fact could be attributed to the reproducibility of the dyeings with this dye, which it was discussed in section 3.2. In this case, the three components (DL, DC and $D H$ ) have influenced in the value of $\mathrm{DE}_{\mathrm{CMC}(2: 1)}$. The positive values of $\mathrm{DC}$ and $\mathrm{DL}$ mean that dyeings were more chromatic and lighter than the replicates.

\section{4- Conclusion}

Synthetic textile effluents containing disperse dyes were treated by means of PVDF ultrafiltration membrane.

The membrane treatment provided up to $90 \%$ and $96 \%$ of COD decrease and dye removal, respectively. In addition, no fouling was observed during the experiments. According to the results in the permeate reuse study, the dyeing performed with $100 \%$ of permeate exhibited similar characteristics than dyeing with softened tap water. The colour differences values were lower than 1 and therefore they met the established acceptance range. Due to the huge amounts of water consumed in the textile industry, the feasibility of UF membranes to treat and reuse textile effluents is a promising result.

\section{Acknowledgements}

The authors thank financial support from the Spanish Ministry of Economy and Competitiveness (CTM2012-31461) and Valentina Buscio is granted by UPC.

\section{References}

[1] A.M. Ferreira, J.A.P. Coutinho, A.M. Fernandes, M.G. Freire, Complete removal of textile dyes from aqueous media using ionic-liquid-based aqueous two-phase systems, Sep. Purif. Technol. 128 (2014) 58-66. 
[2] M. El Haddad, R. Slimani, R. Mamouni, S. ElAntri, S. Lazar, Removal of two textile dyes from aqueous solutions onto calcined bones, J. Assoc. Arab Univ. Basic Appl. Sci. 14 (2013) 51-59.

[3] A. Ahmad, A. Idris, B.H. Hameed, Modeling of disperse dye adsorption onto bamboo-based activated carbon in fixed-bed column, Desalin. Water Treat. 52 (2014) 248-256.

[4] D.S. Ibrahim, A. Praveen Anand, A. Muthukrishnaraj, R. Thilakavathi, N. Balasubramanian, In situ electro-catalytic treatment of a Reactive Golden Yellow HER synthetic dye effluent, J. Environ. Chem. Eng. 1 (2013) 2-8.

[5] S. Apollo, M.S. Onyango, A. Ochieng, Integrated UV photodegradation and anaerobic digestion of textile dye for efficient biogas production using zeolite, Chem. Eng. J. 245 (2014) 241-247.

[6] M.M. Haque, W.T. Smith, D.K.Y. Wong, Conducting polypyrrole films as a potential tool for electrochemical treatment of azo dyes in textile wastewaters., J. Hazard. Mater. 283 (2015) 164-170.

[7] K. Turhan, Z. Turgut, Treatment and degradability of direct dyes in textile wastewater by ozonation: A laboratory investigation, Desalin. Water Treat. 11 (2009) 184-191.

[8] C. Phalakornkule, S. Polgumhang, W. Tongdaung, B. Karakat, T. Nuyut, Electrocoagulation of blue reactive, red disperse and mixed dyes, and application in treating textile effluent., J. Environ. Manage. 91 (2010) 918-26.

[9] S. Zodi, B. Merzouk, O. Potier, F. Lapicque, J.-P. Leclerc, Direct red 81 dye removal by a continuous flow electrocoagulation/flotation reactor, Sep. Purif. Technol. 108 (2013) 215-222.

[10] S.H. Adam, A.A. Jalil, S. Triwahyono, Novel removal of water-insoluble disperse dye onto a low-cost adsorbent prepared from tropical fruit waste, Desalin. Water Treat. 49 (2012) 337-347.

[11] S.M. Burkinshaw, G. Salihu, The wash-off of dyeings using interstitial water. Part 4: Disperse and reactive dyes on polyester/cotton fabric, Dye. Pigment. 99 (2013) 548-560.

[12] Y. Jin, Y. Wu, J. Cao, Y. Wu, Optimizing decolorization of Methylene Blue and Methyl Orange dye by pulsed discharged plasma in water using response surface methodology, J. Taiwan Inst. Chem. Eng. 45 (2014) 589-595.

[13] W. Li, Q. Yue, P. Tu, Z. Ma, B. Gao, J. Li, et al., Adsorption characteristics of dyes in columns of activated carbon prepared from paper mill sewage sludge, Chem. Eng. J. 178 (2011) 197-203.

[14] B. Bonakdarpour, I. Vyrides, D.C. Stuckey, Comparison of the performance of one stage and two stage sequential anaerobic-aerobic biological processes for the treatment of reactive-azo-dye-containing synthetic wastewaters, Int. Biodeterior. Biodegradation. 65 (2011) 591-599. 
[15] I. Vyrides, B. Bonakdarpour, D.C. Stuckey, Salinity effects on biodegradation of Reactive Black 5 for one stage and two stages sequential anaerobic aerobic biological processes employing different anaerobic sludge, Int. Biodeterior. Biodegradation. 95 (2014) 294-300.

[16] M. Riera-Torres, C. Gutiérrez-Bouzán, M. Crespi, Combination of coagulationflocculation and nanofiltration techniques for dye removal and water reuse in textile effluents, Desalination. 252 (2010) 53-59.

[17] C.-Z. Liang, S.-P. Sun, F.-Y. Li, Y.-K. Ong, T.-S. Chung, Treatment of highly concentrated wastewater containing multiple synthetic dyes by a combined process of coagulation/flocculation and nanofiltration, J. Memb. Sci. 469 (2014) 306-315.

[18] Y.-Y. Lau, Y.-S. Wong, T.-T. Teng, N. Morad, M. Rafatullah, S.-A. Ong, Coagulation-flocculation of azo dye Acid Orange 7 with green refined laterite soil, Chem. Eng. J. 246 (2014) 383-390.

[19] S. Barredo-Damas, M.I. Alcaina-Miranda, a. Bes-Piá, M.I. Iborra-Clar, a. IborraClar, J. a. Mendoza-Roca, Ceramic membrane behavior in textile wastewater ultrafiltration, Desalination. 250 (2010) 623-628.

[20] S. Barredo-Damas, M.I. Alcaina-Miranda, M.I. Iborra-Clar, J.A. Mendoza-Roca, M. Gemma, Effect of $\mathrm{pH}$ and MWCO on textile effluents ultrafiltration by tubular ceramic membranes, Desalin. Water Treat. 27 (2011) 81-89.

[21] T. Chidambaram, Y. Oren, M. Noel, Fouling of nanofiltration membranes by dyes during brine recovery from textile dye bath wastewater, Chem. Eng. J. 262 (2015) 156-168.

[22] J. Blanco, F. Torrades, M. Morón, M. Brouta-Agnésa, J. García-Montaño, PhotoFenton and sequencing batch reactor coupled to photo-Fenton processes for textile wastewater reclamation: Feasibility of reuse in dyeing processes, Chem. Eng. J. (2013).

[23] T. Visa, M. Sánchez, V. López-Grimau, R. Navarro, S. Reche, C. GutiérrezBouzán, Photocatalysis with titanium dioxide to remove colour of exhausted reactive dyebaths without $\mathrm{pH}$ modification, Desalin. Water Treat. 45 (2012) 9199.

[24] V. López-Grimau, C. Gutiérrez, M. Sala, M. Crespi, Electrochemical decolourisation of cotton dye baths for reuse purposes: a way to reduce salinity of the textile wastewater, Desalin. Water Treat. 51 (2013) 1527-1532.

[25] A.K. Verma, R.R. Dash, P. Bhunia, A review on chemical coagulation/flocculation technologies for removal of colour from textile wastewaters., J. Environ. Manage. 93 (2012) 154-68.

[26] V. Buscio, M. Crespi, C. Gutiérrez-Bouzán, Sustainable dyeing of denim using indigo dye recovered with PVDF ultrafiltration membranes, J. Clean. Prod. (2014), http://dx.doi.org/10.1016/j.jclepro.2014.12.016. 
[27] V. Buscio, M.J. Marín, M. Crespi, C. Gutiérrez-Bouzán, Reuse of textile wastewater after homogenization-decantation treatment coupled to PVDF ultrafiltration membranes, Chem. Eng. J. 265 (2015) 122-128.

[28] M. Liu, Z. Lü, Z. Chen, S. Yu, C. Gao, Comparison of reverse osmosis and nanofiltration membranes in the treatment of biologically treated textile effluent for water reuse, Desalination. 281 (2011) 372-378.

[29] E. Kurt, D.Y. Koseoglu-Imer, N. Dizge, S. Chellam, I. Koyuncu, Pilot-scale evaluation of nanofiltration and reverse osmosis for process reuse of segregated textile dyewash wastewater, Desalination. 302 (2012) 24-32.

[30] C.S. Ong, W.J. Lau, a. F. Ismail, Treatment of dyeing solution by NF membrane for decolorization and salt reduction, Desalin. Water Treat. 50 (2012) 245-253.

[31] X. Zhu, Y. Zheng, Z. Chen, Q. Chen, B. Gao, S. Yu, Removal of reactive dye from textile effluent through submerged filtration using hollow fiber composite nanofilttration membrane, Desalin. Water Treat. 51 (2013) 6101-6109.

[32] Z. Badani, C. Cabassud, H. Ait-Amar, Membrane separation process for the treatment and reuse of bath dye effluents, Desalin. Water Treat. 9 (2009) 105111.

[33] X. Meng, N. Zhang, X. Wang, L. Wang, D. Huang, R. Miao, Dye effluent treatment using PVDF UF membranes with different properties, Desalin. Water Treat. 52 (2013) 5068-5075.

[34] L. Ji, Y. Zhang, E. Liu, Y. Zhang, C. Xiao, Separation behavior of NF membrane for dye/salt mixtures, Desalin. Water Treat. 51 (2013) 3721-3727.

[35] Standard Methods for the Examination of Water and Wastewater, 22th ed., 2012 American Public Health Association/American Water Works Association/Water Environment Federation, Washington, DC.

[36] AENOR. UNE-EN ISO105-J03, 2009. Test for colour fastness. Part J03: Calculation of Colour Differences. Spanish Association for the Standardization and Certification, Madrid, Spain (in Spanish). 